\title{
Synthesis of Aldehydes from Acyl Chlorides via 1-(Acylmethylamino)-3-methylimidazolium Salts
}

\author{
Maria A. de las Heras, Juan I Vaquero, José L. García-Navio, Julio Alvarez-Builla* \\ Departamento de Qúmica Orgánica, Universidad de Alcalá de Henares, 28871-Alcalá de Henares, Madrid. SPAIN.
}

\begin{abstract}
The reaction of acyl chlorides with 1 -amino-3-methylimidazolium salts, followed by $N$-methylation of the resulting $N$-aminides, afforded 1 -(acylmethylamino)-3-methylimidaz olium salts which, upon treatment with DIBA LH gave aldehydes in good yields. Analogously, dialdehydes were oblained from the corresponding bis-salts.
\end{abstract}

The reduction of acyl halides to aldehydes it is one of the more investigated conversions in organic synthesis. Traditionally performed by hydrogenolysis with $\mathrm{Pd} / \mathrm{BaSO}_{4}$ (Rosemund reaction), many reducing hydrides have been tested, most of them being too reactive to stop the reduction at the aldehyde stage. ${ }^{1}$ The most common reagent, lithium tri- $t$-butoxyaluminium hydride, is particularly convenient for aromatic aldehydes but aliphatic compounds are obtained in only $40-60 \%$ yields. 2,3 Sodium borohydride and its derivatives usually need the use of moderators such as cadmium ${ }^{4,5}$ or copper salts, ${ }^{6}$ with carefully controlled acidity of the reaction medium. ${ }^{7}$ Other hydrides such as $\mathrm{Bu}_{3} \mathrm{SnH}$ or $\mathrm{Bu}_{3} \mathrm{GeH}$, using $\mathrm{Pd}\left(\mathrm{PPh}_{3}\right)_{4}$ as catalyst, ${ }^{8-11}$ and ions of the type $\mathrm{HM}(\mathrm{CO})_{4}^{-}(\mathrm{M}=\mathrm{Fe}, \mathrm{Cr}, \mathrm{W})^{12,13}$ give difficulties in work-up of the reaction mixture, making large scale use inconvenient.

Alternatively, there are several indirect methods for the conversion of acyl halides to aldehydes, most of them going through acylheterocycles, ${ }^{14-17}$ acylsulfonylhydrazides (McFadyen-Stevens reduction) ${ }^{18-20}$ and some amides. ${ }^{21-23}$

We have recently reported that 1-(acylmethylamino)-3-methylimidazolium salts 2 react with Grignard and organolithium reagents to form ketones in good yields. ${ }^{24}$ In addition, the resulting 1-(methylamino)-3methylimidazolium salts 3, can be used to regenerate the salts 2 for a new reaction cycle (Scheme 1).

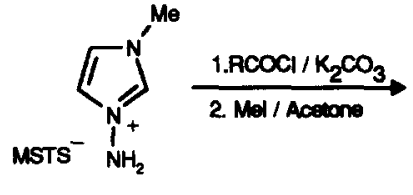

1

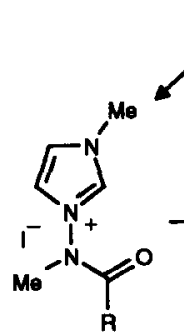

2

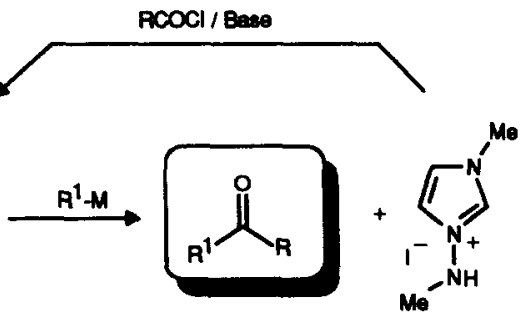

3

Scheme 1 
Initial attempts to demonstrate that the 1-(methylamino)-3-methylimidamolium ylide also acts as a good leaving group with hydride failed, the $\mathrm{N}-\mathrm{N}$ bond usually being cleaved when $\mathrm{LiAlH}_{4}, \mathrm{BH}_{4} \mathrm{Na}$ or $\mathrm{HLiAl}(\mathrm{OEt})_{3}$ were used. However, the formation of the aldehyde was achieved by the use of diisobutylaluminium hydride (DIBALH).

On the basis of this result, we first examined the versatility of the method for the preparation of aliphatic aldehydes and found that the desired products were obtained in good yields, when salts 2 were suspended in THF and treated with a slight excess of the hydride for $\mathbf{3 0} \mathrm{min}$ at room temperature. This procedure also succeeded when used with aromatic and $\alpha, \beta$-unsaturated aldehydes, the yields of which are shown in the Table.

We then prepared the bis-salts 4 by reaction of different di-acyl chlorides with 1-amino-3methylimidazolium mesitilenesulfonate, followed by $\mathrm{N}$-methylation of the aminide thus obtained. Attempted reactions of malonyl chloride and succinyl chloride with the imidazolium derivatives 1 , failed under different conditions, probably due to acidity of the methylene protons or charge interactions.

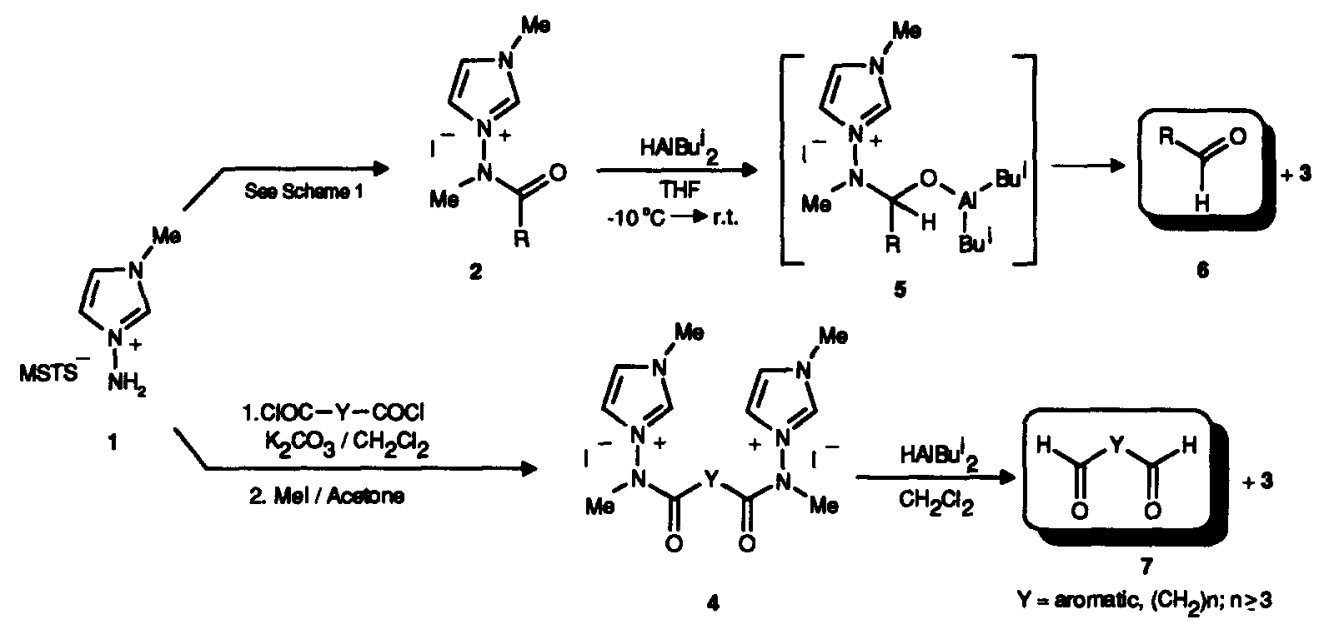

Scheme 2

With salts 4 in hand, we next studied their reaction with DIBALH. Reaction in THF gave disappointing results, attributed to the insolubility of the salts in this solvent. However, when the process was performed in $\mathrm{CH}_{2} \mathrm{Cl}_{2}$, in which the salts were partially soluble, the corresponding dialdehydes 7 were also obtained in good yields.

In a typical procedure, a solution of $2(0.5 \mathrm{mmol})$ in THF $(2 \mathrm{ml})$ was cooled to $-10^{\circ} \mathrm{C}$ and treated with $0.55 \mathrm{mmol}(1 \mathrm{M}$ in THF) of DIBALH under argon. The mixture was allowed to warm to room temperature over $30 \mathrm{~min}$ and then quenched with $5 \%$ hydrochloric acid $(1 \mathrm{ml})$. The mixture was diluted with water (10 $\mathrm{ml})$ and extracted with $\mathrm{Et}_{2} \mathrm{O}(3 \times 10 \mathrm{ml})$. The organic phase was dried $\left(\mathrm{Na}_{2} \mathrm{SO}_{4}\right)$, filtered and concentrated in vacuo to give a residue which was purified by column chromatography on silica gel (petroleum ether/EtOAc, 9:1) to afford the pure aldehyde. Dialdehydes were obtained from $4,{ }^{25}$ using 2.1 equivalents of DIBALH in $\mathrm{CH}_{2} \mathrm{Cl}_{2}$, after $30 \mathrm{~min}$ stirring at room temperature and the usual workup. From the aqueous phase the salt 3 can be easily recovered by simple removal of water under reduced pressure. 
Table. Aldehydes 6 and dialdehydes 7 prepared.

\begin{tabular}{|c|c|c|c|}
\hline Compound & $\mathbf{R}$ & $\mathbf{Y}$ & Yield $(\%)^{a}$ \\
\hline $6 \mathbf{a}$ & $\mathrm{CH}_{3}\left(\mathrm{CH}_{2}\right)_{8^{-}}$ & - & 83 \\
\hline $6 b$ & & - & 72 \\
\hline $6 \mathrm{c}$ & $\mathrm{CH}_{2}=\mathrm{CH}\left(\mathrm{CH}_{2}\right)_{8-}$ & - & 69 \\
\hline 6d & $\mathrm{C}_{6} \mathrm{H}_{5}$ & - & 77 \\
\hline $6 e$ & & - & 75 \\
\hline $6 f$ & 4-Cl- $\mathrm{C}_{6} \mathrm{H}_{4}$ & - & 76 \\
\hline $6 \mathrm{~g}$ & $4-\mathrm{O}_{2} \mathrm{~N}-\mathrm{C}_{6} \mathrm{H}_{4}$ & - & 78 \\
\hline $6 \mathrm{~h}$ & $4-\mathrm{CH}_{3}-\mathrm{C}_{6} \mathrm{H}_{4}$ & - & 80 \\
\hline $6 \mathbf{i}$ & $\mathrm{C}_{6} \mathrm{H}_{5}-\mathrm{CH}=\mathrm{CH}-$ & - & 80 \\
\hline $7 \mathbf{a}$ & - & $-\left(\mathrm{CH}_{2}\right)_{3}-$ & 72 \\
\hline $7 \mathrm{~b}$ & - & $-\left(\mathrm{CH}_{2}\right)_{6}-$ & 77 \\
\hline $7 c$ & - & $-\left(\mathrm{CH}_{2}\right)_{7^{-}}$ & 78 \\
\hline $7 d$ & - & & 82 \\
\hline
\end{tabular}

a Yields refer to isolated pure product after column chromatography.

In conclusion, the conversion of acyl halides to aldehydes via 1-(acylmethylamino)-3-methylimidazolium salts seems to be a general procedure when DIBALH is used as reducing agent. In addition, the 1(methylamino)-3-methylimidazolium salt, easily recovered as a byproduct, opens the way for easy recycling, thus making the whole process suitable for industrial scale.

Acknowledgement. The authors are grateful for grant (MAH) from Ministerio de Educación y Ciencia and financial support from Comision Interministerial de Ciencia y Tecnología (CICYT) through the project PB90-0284 


\section{REFERENCES AND NOTES}

1. Jonhstone, R. A. W. Reduction of Carboxylic Acids to Aldehydes by Metal Hydrides in Comprehensive Organic Synthesis; Trost, B.; Fleming, I. Eds. vol. 8, p. 236-254, Pergamon Press, Oxford, 1991.

2. Brown, H. C.; McFarlin, R. F. J. A m. Chem. Soc. 1958, 80, 5372.

3. Brown, H. C.; Subba Rao, B. C. J. Am. Chem. Soc. 1958, 80, 5377.

4. Johnstone, R. A. W.; Telford, R. P. J. Chem. Soc., Chem. Comm. 1978, 354.

5. Entwistle, D.; Boehm, P.; Jonstone, R. A. W.; Telford, R. P. J. Chem. Soc., Perkins Trans.I 1980, 27.

6. Sorrel, T. N.; Pearleman, P. S. J. Org. Chem. 1980, 45, 3449.

7. Hutchins, R. O.; Markowitz, M. Tetrahedron Lett. 1980, $21,813$.

8. Guibe, F.; Four, P.; Rivière, H.; J. Chem. Soc., Chem. Comm. 1980, 432.

9. Four, P.; Guibe, F. J. Org. Chem. 1981, 46, 4439.

10. Neumann, W. P. Synthesis 1987, 665.

11. Geng, L. J. Organomet. Chem. 1989, 376, 41.

12. Cainelli, G.; Manescalchi, F.; Umani-Ronchi, A. J. Organomet. Chem. 1984, 276, 205.

13. Kao, S. C.; Gaus, P. L.; Youngdahl, K.; Darensbourg, M. Y. Organometallics 1984, 3, 1601.

14. Staab, H. A.; Braïnling, H. Justus Liebigs Ann. Chem. 1962, 654, 119.

15. Ramegowda, N. S.; Modi, M. N.; Koul, A. K.; Bora, J. M.; Narang, C. K.; Mathur, N. K. Tetrahedron $1973,29,3985$.

16. Izawa, T.; Mukaiyama, T. Bull. Chem. Soc. Jpn. 1979, 52, 555.

17. Nagao, Y.; Kawabata, K.; Seno, K.; Fujita, E. J. Chem. Soc., Perkin Trans.I 1980., 2470.

18. Babad, H.; Herbert, W.; Stiles, A. W. Tetrahedron Lett. 1966, 2927.

19. Matin, S. B.; Craig, J. C.; Chan, R. P. K. J. Org. Chem. 1974, 39, 2285.

20. Dudman, C. C.; Grice, P.; Reese, C. B. Tetrahedron Lett. 1980, 21, 4645.

21. Weygand, F.; Eberhardt, G. Angew. Chem. 1952, 64, 458.

22. Weygand, F.; Eberhardt, G.; Linden, H.; Schäfer, F.; Eigen, I. Angew. Chem. 1953, 65, 525.

23. Nahm, S.; Weinreb, S. M. Tetrahedron Lett. 1981, 22, 3815.

24. Heras, M.A.; Molina, A.; Vaquero, J. J.; Garcia-Navio, J. L.; Alvarez-Builla, J. J. Org. Chem. 1993, 58, 5862

25. Bis-salts 4 were prepared as follows: To a mixture of 1 ( $1 \mathrm{mmol}, 0.29 \mathrm{~g}$ ) and $\mathrm{K}_{2} \mathrm{CO}_{3}$ ( $4 \mathrm{mmol}, 0.55$ $\mathrm{g})$ in $\mathrm{CH}_{2} \mathrm{Cl}_{2}(10 \mathrm{ml})$ was added the corresponding diacyl chloride $(0.6 \mathrm{mmol})$ and the mixture was stirred at room temperature for $18 \mathrm{~h}$. The inorganic salts were filtered and washed with $\mathrm{CH}_{2} \mathrm{Cl}_{2}$. The filtrate and organic layer were concentrated under vacuum to give the ylide as a yellow oil. The crude ylide was dissolved in acetone $(10 \mathrm{ml})$ and methyl iodide $(0.56 \mathrm{~g}, 4 \mathrm{mmol}$,) was added. The solution was stirred at reflux for $24 \mathrm{~h}$ and the white precipitate formed was filtered and crystallized from ethanol to afford pure bis-salts 4 (4a:59\%; 4b:67\%; 4c:60\%; 4d:70\%). 4a: mp. 189-190 ${ }^{\circ} \mathrm{C}$; IR (KBr) $v_{\max } 3142,3059,1707,1576,1213,1033 \mathrm{~cm}^{-1}{ }^{1} \mathrm{H}$ NMR (300 MHz, DMSO-d 6 ) $\delta 1.7-1.8(\mathrm{~m}, 2 \mathrm{H}) ; 2.0-$ $2.5(\mathrm{~m}, 4 \mathrm{H}) ; 3.42(\mathrm{~s}, 3 \mathrm{H}) ; 7.82(\mathrm{~s}, 1 \mathrm{H}) ; 8.00(\mathrm{~b}, 1 \mathrm{H}) ; 9.46(\mathrm{~b}, 1 \mathrm{H}) \mathrm{ppm}$. 